\title{
A Case Study on Positive Function of Intentional Ambiguity in English
}

\author{
Liu Ying
}

\begin{abstract}
Ambiguity as a universal linguistic phenomenon is concerned with every aspect of language, and it can be classified into various types in different standards and perspectives. According to the utterance motivations and effects, ambiguity can be classified into intentional and unintentional ambiguity belongs to pragmatic failure, which influences the normal communication and needs to be disambiguated. Intentional ambiguity is necessary for people to pay some special attention. The research objective of the paper is intentional ambiguity and the paper is going to research and analyze the positive function of intentional ambiguity from advertising, literary works, daily talks, political speeches, etc. The paper aims to state the positive function of intentional ambiguity and then find out the potential value of it in communication.
\end{abstract}

Index Terms-Ambiguity, intentional ambiguity, positive function.

\section{INTRODUCTION}

As a communication tool, English is as ambiguous as the rest language of the world. In daily communication, because of the specific languages environment, we often come across some expressions which can be interpreted as two or more meanings. That is an ambiguous phenomenon. As [1] states: "Ambiguity is a common language phenomenon, just as common as the flu in the pathology". Keith and Dutch, they also put forward the view of "language is ubiquitous" in his monograph Ambiguity in Psycholinguistics, "Upon careful consideration, one can not but be amazed at the ubiquity,we can not but wonder the ubiquitous language ambiguity." Compared with some other western languages, the vocabulary of English is large, the suffix is less, the homophone is tens of thousands, and grammatical flexible syntax is loose, which provides a great possibility for the English ambiguity. Due to language users themselves or language structure defects, ambiguity leads to communication difficulties or communication barriers. However, we always strive to be "accurate, concise, vivid" to express our thoughts, views and attitudes when we are speaking or writing, so that the listeners or the readers can correctly and comprehensively understand the content we want to express and to avoid misunderstanding.

Although unintentional ambiguity will bring obstacles or even influence language communication activities by revealing the contradiction of language structure. As the proverb says "Every coin has two sides", if we can use the

Manuscript received August 22, 2019; revised September 16, 2019. This work was supported in part by the School of Foreign Languages at Northwestern Polytechnical University.

Liu Ying is with the School of Foreign Languages, Northwestern Polytechnical University, China (e-mail: naomi1212@mail.nwpu.edu.cn). positive function of contradictions in the language structure, it will surely enable us to produce a special effect which can help us to achieve special communicative purposes.

And this paper aims to discuss the positive function of intentional ambiguity. In the communicative activities, one of the most difficult points for most of the learners is the special effect achieved by intentional ambiguity. Usually, it is the deliberate arrangement of the speakers. In order to make intriguing content, or unexpected dramatic effect, they just try to reflect those effects through a variety of language means in the voice, vocabulary, syntax at different levels.

Therefore, this paper focuses on the positive function of ambiguity in English. By analyzing samples in different occasions, the author would like to let people know more about the positive function of intentional ambiguity.

\section{LITERATURE REVIEW}

\section{A. Types of Ambiguity}

Ambiguity can be classified into various types in different standard and perspectives. Among them, two types is to be mentioned in [2]. One is to classify ambiguity into phonological ambiguity, lexical ambiguity, syntactic ambiguity, and pragmatic ambiguity on the linguistic level. The other one is to classify ambiguity into intentional ambiguity and unintentional ambiguity according to the utterance motivation and effects.

\section{B. Intentional Ambiguity in English}

The old form of studying Rhetoric was too concerned with the mechanics of formulating arguments and with conflict are shown in [3]; instead, he proposed the New Rhetoric to study of the meaning of the parts of discourse, as "a study of misunderstanding and its remedies" to determine how language works. That ambiguity is expected, and that meanings are not inherent in words, but is inherent in the perception of the reader, the listener, and the viewer. By their usages, compiled from experiences, people decide and determine meaning by "how words are used in a sentence", in spoken and written language.

Here the paper is going to talk about types of intentional ambiguity caused by different reasons. First, intentional ambiguity is caused by voice. In the use of voice manufacturing, homonyms are often used for conscious clever arrangements. They pronounce the same or similar, but a different meaning, often makes people misunderstand things. Using intentional ambiguity is a good way to create humor, a pair of homonyms in the same sentence. Second, vocabulary ambiguity is caused by vocabulary. As [4] said, intentional ambiguity is caused not only in the same word 
with different pronunciations but also produced in the words with different meanings, that is, the word polysemy. So the exact meaning of a word must be judged according to its context. The context is different, or the context is unknown, or deliberately confused, and then there is a pun or a special communication effect. Third, the intentional ambiguity caused by the syntactic structure. Different interpretations of syntactic relations can also produce the effect of deliberate ambiguity, that is, within the same sentence because of the existence of different internal syntax and can make a different interpretation, resulting in deliberate ambiguity. Fourth, intentional ambiguity caused by context. In real life, we cannot only use the context to eliminate negative ambiguity, but also use the context to deliberately create intentional ambiguity, in order to achieve a specific communicative effect.

\section{Previous Studies on Intentional Ambiguity in English}

Researches on English ambiguity can be tracked back to 20th century. Many western scholars showed a big interest in the topic and proposed their unique opinions. As it is shown in [5], seven types of ambiguity is a work of literary criticism by William Empson which was first published in 1930. it was one of the most influential critical works of the 20th century and was a key foundation work in the formation of the New Criticism School. The book is organized around seven types of ambiguity that Empson finds in the poetry he criticises. He discussed that interpreting ambiguity was the basic task of semantics. It shows that ambiguity is important in translation. We will meet many puzzles when ambiguity appears in our target language.

Therefore, eliminating the negative ambiguity is necessary in our process of translation. Reference [6] said that ambiguity is a common language phenomenon, just as a flu in pathology. Kess, F.J. \& Hoppe, A.R. proposed in their monograph Ambiguity in Psycholinguistics that "Upon careful consideration, one cannot but be amazed at the ubiquity of ambiguity in language." Although we don't have to extremely understand the universality of ambiguity, but its objective existence in language is of no doubt. Our forefathers proposed that ambiguity is everywhere though the connection of world at that time is not as close as now. They realized the importance of the ambiguity. Therefore, we should further study on ambiguity not only on eliminating the negative ambiguity. Chomsky uses Trace Theory to analyze ambiguity. Another linguist shows his opinion in [7], he thinks ambiguity is that there is a one-to-many relationship between syntax and significance. Kempson points out that: "a word and a sentence may contain more than one meaning." Leech from Britain defines the ambiguity as "a language item has more than one cognitive significance." they have made great contribution to the development of linguistic as they provided research methods and lay the foundation for later generations. In recent 10 years, linguistics in our country researched a lot in this aspect. Many previous studies in China focused on the elimination of ambiguity or the classifications of ambiguity. They analyzed ambiguity from cognitive, semantic, syntactic and pragmatic perspectives. And the most elementary principle applied by them is the Transformational Generative Grammar by Chomsky.
Reference [8] classified types of ambiguity from grammatical, semantic, and pragmatic perspectives in the article and points out the current situation of ambiguity research, the article suggests that we should further study on ambiguity not remain the studies on the classification of ambiguity. As the author is interested in the the positive function of intentional ambiguity, after collected materials like [9]. the author realized intentional ambiguity is not only important in literal works, but also necessary in our daily life. Reference [10] focuses on the pragmatic value of intentional ambiguity, and it introduces both unintentional ambiguity and intentional ambiguity in his article. It is necessary for us to deal with the ambiguity from opposite perspectives since we need to eliminate the negative ambiguity, we need to utilize the positive ambiguity to make our language more various.

\section{Methodology}

\section{A. Research Questions}

(1) What are the features of intentional ambiguities in English?

(2) How do these intentional ambiguities realized linguistically to achieve their features?

\section{B. Research Objects}

The research objects of this paper is intentional ambiguity and the paper will research and analyze the positive use of intentional ambiguity from advertising, literary works, daily talks, political speeches, etc.

\section{Research Design}

The author aims to state the positive function of ambiguity of ambiguity from pragmatic perspective in order to find the pragmatic value of intentional ambiguity. The paper is going to take American novel The Great Gatsby, English advertisements, daily talks as examples to analyze different aspects of intentional ambiguity, and then provide individual features of intentional ambiguity in English and how the features are achieved.

\section{Case Analysis of Intentional Ambiguity IN ENGLISH}

In many situations, intentional ambiguity can help people to achieve particular effects such as humor, satire, rhetoric and etc. This part focuses on humorous effect, satirical effect and rhetorical effect achieved by intentional ambiguity.

\section{A. Humorous Effect}

Humor is a good flavor in life, especially when we want to melt embarrassing or turn a serious situation into an easy one. Intentional ambiguity is one of the ways we can use it to make humor. Below is an example of using intentional ambiguity to make humor.

Fitzgerald uses many ambiguity examples in his masterpiece The Great Gatsby. This selected part is particularly interesting. The content is as following [11]:

"Come to lunch someday," he suggested, as we groaned down in the elevator.

"Where?" 
"Anywhere."

"Keep your hands off the lever," snapped the elevator boy.

"I beg your pardon," said Mr. McKee with dignity, "I

Don't know I was touching it."

"All right," I agreed, "I'll be glad to."

"...I was standing beside his bed and he was sitting up between the sheets, clad in his underwear, with a great portfolio in his hands".

"Beauty and the Beast...Loneliness...Old Grocery Horse...Brook'n Bridge..."

"Then I was lying half asleep in the lower level of the Pennsylvania Station, staring at the morning Tribune, and waiting for the four o'clock train."

In this novel, there is enough ambiguity to lead to a reading in which the narrator, Nick Carraway. There are a few significant words in the passage, such as the choice of "groaned" and the juxtaposition of Mr. MacKee saying he didn't know he was touching the lever with Carraway saying "I'll be glad to." this is the first time Fitzgerald uses ellipses in the book, and they seem to indicate an event that leads to Mr. McKee sitting in bed only in his underwear.

In short, if you meet ambiguity when learning English, we should try to not only eliminating negative ambiguity, but also appreciating the communicative effect produced by intentional ambiguity. We should realize that humor is the embodiment of wisdom. Intentional ambiguity embodies the use of language skills, and the ability to understand and appreciate this unique language phenomenon also requires skill. We can find the charm of intentional ambiguity through masterpiece and daily conversations, then we can try to use it to make the language effect, which can also improve our enthusiasm for language learning from another perspective.

\section{B. Satirical Effect}

We have always heard about some small stories about famous writers who have successfully used writing devices to satirize current social environment or his government's foolish policies, using ambiguity is a favorable way which was chosen by most of them. A well-known saying becomes well- known because it can always use simple words to reflect some profound meanings.

Here are two examples of word "lie". by using the different meanings of this word, the sentence expresses satirical effects. The first one is "an ambassador is an honest person who lies abroad for the good of the country."

Lie has many different meanings, such as living or telling something that is not true. This sentence can be translated into an ambassador is an honest man who lives abroad for the good of the country, or an ambassador is an honest person who cheating others abroad for the good of his country. Through this two kinds of understanding, the author satirizes the ambassador's responsibility incisively and vividly.

The second example is as follows: "A: What do lawyers do when they die? B: Lie still." in this case, "Lie" and "Still" play a key role in this conversation. Literally, it means "They are lying quietly after death", but it can also express "They died but they still lying." it is clear that the speaker means the latter, satirizing lawyers that they are always doing something dishonest in the name of the law.
Also, by using intentional ambiguity, writers could satirize politics on the side of people. Here's an example: "I finally figures out how government works, the Senate gets the bill from the House. The president gets the bill from the Senate. And we get the bill for everything."

In this sentence, the first and the second "bill" mean drafts of a law, however, the third "bill" means a request for payment. The author uses two different meanings of "bill" to satirize rules of government that they don't care about people's benefit, and only focus on theirs. by using intentional ambiguity, this sentence exactly express the grievance of people.

In the production of irony, the use of intentional ambiguity can be said as a knife which is as sharp as a sword. This is the embodiment of language skills, so that the attack is more intelligent. A long time ago, our ancestors used intentional ambiguity to speak for vulnerable groups and attack power politics. As for us, we don't have to do things like them, but using intentional ambiguity is a good way to improve our language skills.

\section{Rhetorical Effect}

In the process of English communication, accurate information is passed, such as national policy, business letter, contractual contract in some occasions there is no need of ambiguity. But in some specific occasions, due to special reasons, people do not want to express the true meaning straightly, intentional ambiguity in language is a perfect way to avoid this, especially we need to rely on puns to achieve the desired pragmatic effect. The use of the pun is wide, not only used in literary works, daily communication, but also used in advertisements and other aspects. The part will mainly introduce the puns caused by intentional ambiguity in advertisements.

\section{1) Pun}

This phenomenon often appears in advertising words and propaganda, because by using ambiguity. The content of the advertisement is more concise and overstretched. Below are several advertisements selected for showing the special effect made by pun.

First one is "More sun and air for your son and heir."

This is a piece of advertisement for the beach bath. In the sentence, because the clever use of intentional ambiguity: "sun" and "son", "air" and "heir", a humor have occurred. So that it's easy to move the parents' hearts' for their children.

Here is an advertisement of Coca Cola: "Coke refreshes you like no other can." in this advertisement, "can" can be seen as a variety of beverages cans of drinks, it can also be understood as an omitted verb of the subordinate clause. For the former, this sentence is: "Coke refreshes you like no other can (can refreshes you), this "can" on behalf of canned drinks. For the latter, the meaning is: Coke refreshes you like no other (drinks) can (refresh you), this "can" for the omitted verb. This advertisement is rich in text and interesting by using intentional ambiguity. Compared with other advertisements, it can easily catch customers' eyes.

Linguists argue that ambiguity has a negative effect on semantic comprehension and should be avoided as much as possible because it causes misunderstandings that can cause an obstacle. M. H. Abrams describes ambiguity as "a flow in 
style, without any literary value." but there are a few experts think that ambiguity is a positive phenomenon, has its own practical value, sometimes we can see the richness and flexibility of language from ambiguity.

\section{2) Euphemism and implication}

This function of ambiguity is a good way to avoid conflicts and sometimes a big fight. From daily communication between friends and families to negotiate between two states, it can be used as a good strategy to maintain a good relationship or getting an agreement without losing your interests. In daily life, people, people in order to achieve a certain purpose, often actively and consciously use the language of rhetorical devices. Although the ambiguous phenomenon will make the semantic complex, but not necessarily cause misunderstanding. Among the two kinds of disagreement, if there is a kind of out of the ordinary, it is not difficult to know the speaker's true meaning, and often caused as a funny joke, to produce special effects.

Here is an example: "You are not eating your fish." the waitress said to him, "Anything wrong with it?" "Long time no see." the man replied. The customer in this example is very smart, he successfully expressed his feeling without causing embarrassment to the waitress. "Sea" and "See" is a pair of homonyms. The customer seemed to express there was a long time not seeing, but the true meaning was the fish was not fresh. He expressed his dissatisfaction and criticism in a euphemistic way by using intentional ambiguity.

Look at this example: "Not I, believe me. You have dancing shoes with nimble soles; I have a soul of lead so stakes me to the ground. I cannot move." In this example, "Sole" and "soul" is a pair of homonyms. "sole" means "flat bottom part of a shoe", and "soul" means "soul, spirit". This contrasts sharply, because other people have light soles(nimble soles), but he has a lead-like soul and this contrast achieved by intentional ambiguity reflects his great pain.

Ambiguity can be a powerful tool in literature when an author uses it intentionally. Ambiguous situations can force the reader to decide what happens in a story for him or herself. This decision about which interpretation to choose thus reflects on the readers' own psychology. If a reader is an optimistic person, for example, she or he might decide that things ended well, or if the reader has recently gone through a bad breakup he or she might decide that a betrayal was intentional rather than accidental. Authors sometimes write ambiguous endings in their books precisely to create situations that ask the reader to bring their own experience to bear to decide what happened. Many philosophers have explored the nature of ambiguity, and have concluded that it is an inevitable part of human existence. Psychologists have also researched how people deal with and tolerate ambiguity; being able to tolerate ambiguity seems to be an important element for creativity and being open-minded. Thus, while ambiguity can occur at the sentence level in literature, the ambiguity presented in characters' motivations and in plot lines can be important to help readers develop their own tolerance for it and thus their psychological well-being.

By giving and analyzing all these cases, the positive function of intentional ambiguity will be revealed to people.
Therefore, we can use intentional ambiguity in our daily life or literal works to make special effects which we need. Also, in English communication effect, realize that humor is the embodiment of wisdom. Intentional ambiguity embodies the superiority of intelligence, and the ability to understand appreciate this unique language phenomenon also requires wisdom. In the basic ability of students to a certain level, so that they try to use their own structure in the communication, to experience its effect, from another point of view to improve their enthusiasm for language learning.

\section{CONCLUSION}

\section{A. Major Findings}

Ambiguity is a good example of the contradiction between the form and the meaning that exists in natural language. We often encounter a variety of difficulties brought by it when during the understanding and application of language. However, besides careful study of ambiguity reasons, in order to better explain and use ambiguity, we should pay attention to its positive function. Because ambiguity is not only meaningful for language interpretation, we should pay attention to its positive function. Because ambiguity is not only meaningful for language interpretation, writing and translation, but also plays an active role in the development of linguistic theory. In short, ambiguity is unique language phenomenon, and it is not only in literary works but also in daily communication of practical significance.

\section{B. Limitations of the Study}

This paper only discusses two categories of English ambiguity and the application of ambiguity, summarizes and studies the charm of intentional ambiguity.

\section{Implications}

In English teaching, analysis of ambiguity can help students understand the language structure and the use of language rules, improve the ability to understand and use language, so that the language in the actual exchange of the correct use, and intentional use of ambiguity, let the students find the special language effect produced in literary works can better grasp the the essence of literary works; in daily life, if intentional ambiguity is used correctly and skillfully, it may help us to avoid the conflict, make the conversation more humorous, or making a more compelling speech in public. English ambiguity has advantages and disadvantages. Ambiguity is sometimes unintentional, in which case ambiguity should be avoided and eliminated; Sometimes it is intentionally created, using language ambiguity to achieve a certain expression. Its "harm" is the sentence is vague, so listeners or readers cannot correctly capture the meaning of conversation in the communication, under this situation, unintentional ambiguity should be avoided or eliminated. And sometimes the ambiguity of this phenomenon was deliberately used for the language by glory, we call it intentional ambiguity. Speakers actively utilize language contradictions to create ambiguity, the rhetorical device of pun, or to make the humorous effect. In order to achieve a specific purpose of communication. So make a full use of 
ambiguity cannot only increase the effect of expression but also shows the witty skills and beautiful sense.

In addition, it is a known fact that Chinese people particularly like to use ambiguous language in oral and written forms. To a certain extent, we are very envious of the ability to express our ideas in ambiguous words, and we always like to figure out the real thoughts that others hide behind the literal meaning. Therefore, the analysis of English ambiguity will enable us to better understand cultural differences between China and western.

\section{ACKNOWLEDGMENT}

I would take this opportunity to express my sincere thanks to all those who offered me great help. This thesis would not have been finished without them.

My deep appreciation should also go to all the teachers in the school of foreign languages from Northwestern Polytechnical University, who have instructed various courses, which have greatly enlarged my knowledge as well as the scope of my thesis. This paper is completed under the guidance of my supervisor. Her profound professional knowledge, rigorous attitude, improving work style, the tireless in teaching and the noble morality have profound influence on me. Not only make me set a lofty goal of learning, master the basic research methods, but also make me understand a lot of things to do. In this regard, I would like to express my high respect and heartfelt thanks to her. And then, I want to thanks my classmates.

In the process of writing the paper, a lot of problems can not be solved without the help of all these people. Finally, I would like to show my sincere thanks to my parents and all my friends who always inspire me in my study and give me support.

\section{REFERENCES}

[1] L. Robert, An Ambiguity-Based Theory of the Linguistic Verbal Joke in English, Adam Mickiewicz University, 1996.

[2] E. Laura, A Study of Potential Sources of Linguistics Ambiguity in Written Work, Sandia National Laboratories, 2009.

[3] I. Richard, The Philosophy of Rhetoric, London: Oxford University Press, 1936.

[4] Z. L. Hu, Linguistics: A Course Book, Beijing: Beijing University Press, 2011

[5] K. Dutch, Ambiguity in Psycholinguistics, Benjamins Publishing Company, 1981.

[6] J. Pere, Ambiguity in Linguistic Theory, Metalogicon, 2010

[7] D. Ma, A Grammatical Analysis of Intentional Ambiguity of English, Chonhqing Polytechnic College, 2013.

[8] E. William, Seven Types of Ambiguity, New Directions, 1930.

[9] S. Sarah, Linguistic Ambiguity in Langugae-Based Jokes, DePaul University, 2009.

[10] Z. Y. Suo, Pragmatics, Beijing: Beijing University Press, 2014.

[11] F. S. Fitzgerald, The Great Gatsby, 1925.

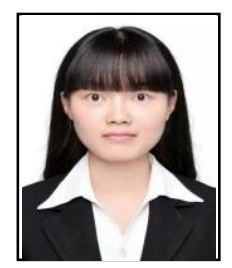

Liu Ying comes from Xi'an city of Shaanxi province. She was born in 1995. She got her bachelor degree in Xi'an Poletechnic University in 2017, and now she is a master degree student of applied linguistics at Northwestern Polytechnical University.

Her previous part-time jobs are all English teachers, such as assistant English teacher at Wendou company in Changan district of Xi'an city, online English teacher at Yuanfudao in Xi'an city.

Ms. Liu was the winner of the Third Prize Award in the preliminary round of 2015 "FLTRP" English Writing Contest, the Outstanding Volunteer in 2014-2015 at Xi' an Polytechnic University, the Third Prize Award in 2015 Xi'an Polytechnic University Model United Nations, the Excellent Graduate in Xi'an Polytechnic University in 2017, the Second Prize Award of Academic Scholarship for master degree students in 2017, the Second Prize Award of Academic Scholarship for master degree students in 2018. 